Geografia e Ordenamento do Território, Revista Electrónica

Centro de Estudos de Geografia e Ordenamento do Território

http://cegot.org

ISSN: 2182-1267

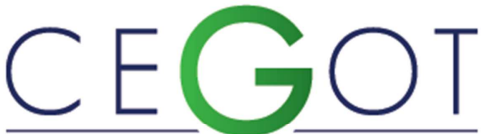

Centro de Estudos de Geografia e Ordenamento do Território
DOMINGUES, RITA

Universidade Federal Rural de Pernambuco,

Departamento de História (DEHIST)

Rua Dom Manuel Medeiros, s/n, Dois Irmãos. CEP: 52171-900,

Recife, Brasil

ritaalcantara@outlook.com

\title{
Ordenamento territorial, governança e a transposição de águas do São Francisco: uma perspectiva ${ }^{1}$
}

Land use planning, governance and water transposition of San Francisco: a perspective

Referência: Domingues, Rita (2015). Ordenamento territorial, governança e a transposição de águas do São Francisco: uma perspectiva. Revista de Geografia e Ordenamento do Território (GOT), n.o 8 (dezembro). Centro de Estudos de Geografia e Ordenamento do Território, p. 51-74, dx.doi.org/10.17127/got/2015.8.004

\section{RESUMO}

O rio São Francisco assume funções além do espaço local, atingindo a dimensão regional quando seus usos são disputados com a geração de energia elétrica, com a irrigação e, no momento, com o projeto de ordenamento territorial da transposição de águas do rio São Francisco. Este artigo objetiva construir uma análise do processo de participação da sociedade na definição desse projeto governamental. No arcabouço teórico, destaca-se o entendimento sobre ordenamento territorial, governança e instituições, pensados de forma combinada a partir do contexto brasileiro. O encadeamento da pesquisa fundamenta-se numa análise crítica. Fez-se pesquisa bibliográfica e de campo para entendimento da questão. Pauta-se este estudo no reconhecimento de que a perspectiva teórica adotada possibilita a compreensão do envolvimento da sociedade no processo.

Palavras-chave: Região Semiárida, Transposição, Ordenamento Territorial, Governança, Sociedade.

\footnotetext{
${ }^{1}$ Adaptado do capítulo "Transposição: acirramento dos conflitos", trabalho defendido como tese de doutoramento à UFRJ.
} 


\section{ABSTRACT}

The São Francisco river takes on functions beyond the local area, reaching the regional dimension when its uses are played with the generation of electricity, irrigation and, at the time, to land use planning project of the São Francisco River water diversion. This article aims to build an analysis of the company's participation process in defining this government project. In the theoretical framework, there is the understanding of spatial planning, governance and institutions, designed in combination from the Brazilian context. Search The chain is based on a critical analysis. There was literature and field research to understand the question. Is guided this study in recognition that the theoretical approach adopted furthers our understanding of the involvement of society in the process.

Keywords: Semiarid region, Transposition, Territorial planning, Governance, Society.

\section{Introdução}

Apesar de o Brasil se encontrar numa posição confortável quanto à disponibilidade de água doce ( $20 \%$ da vazão de todos os rios da Terra), isso não é impedimento para a existência de conflitos, posto que essa disponibilidade de água aparece com grande desigualdade regional, seja em termos de qualidade ou, principalmente, de quantidade. É exatamente a situação encontrada no Nordeste semiárido, com cerca de $40 \%$ da população da região e um quadro de escassez relativa, onde a bacia do São Francisco ${ }^{2}$ representa em torno de $70 \%$ de sua disponibilidade total, convertendo-se numa matriz de possibilidades estratégicas, da qual depende toda população.

Entretanto, o fantasma da seca esteve e continua presente, acompanhando a história dessa região quando, nos anos 1950 - década em que a região vivenciou duas grandes secas -, seguindo orientação de Celso Furtado (1967 e 1985), em busca dos problemas reais e de soluções, foi instituído o Grupo de Trabalho para o Desenvolvimento do Nordeste (GTDN), dando origem, a seguir, a uma nova organização, a Superintendência de Desenvolvimento do Nordeste (Sudene), no final da década. Para essa instituição, o problema central da região era de caráter econômico, e a estratégia governamental seria via industrialização.

Esse modelo de planejamento regional ou ordenamento territorial é estabelecido por meio de um campo de forças com o poder centralizador do Estado, desejoso de impor de cima

\footnotetext{
${ }^{2}$ A bacia do rio São Francisco representa apenas 1,7\% da disponibilidade hídrica do país.
} 
um modelo de organização fundamentado no controle e domínio do espaço. A definição de ordenamento do território, entendida como uma política pública, deve ser posta em confronto com as reflexões de ordem econômica e política envolvidas, segundo Lacaze (1995, p.23-27), uma vez que a organização dos poderes públicos e a ação econômica são as duas grandes séries de meios de ação utilizáveis.

Na mesma linha de raciocínio e aprofundando o entendimento, Ferrão (2011, p. 34) afirma que um sistema de ordenamento territorial envolve e reflete, ao mesmo tempo, as condições políticas, sociais, econômicas e institucionais de uma sociedade em particular, por isso, deve ser entendido à luz de contextos singulares em que foi concebido.

Mais recentemente, nos primeiros anos do século XXI, o governo traçou outro grande plano de ordenamento territorial, o projeto de Transposição de parte das águas do São Francisco ou Projeto de Integração da Bacia do Rio São Francisco e das bacias hidrográficas do Nordeste Setentrional, o qual vem sendo apresentado como alternativa para reduzir a oferta desigual de água na região (EIA/Rima, 2000).

Partindo desse entendimento, este artigo objetiva construir uma análise crítica sobre a participação da sociedade na definição do projeto governamental brasileiro de transposição de águas do Rio São Francisco.

Assim, as questões seguintes norteiam a reflexão:

1. Em que medida existiu a aplicabilidade da governança no momento que antecedeu o projeto de transposição do Rio São Francisco?

2. Em que medida a sociedade foi envolvida no processo?

3. Em que medida o resultado final foi diferente do modelo de governo clássico, sem consulta à sociedade?

No arcabouço teórico, aprofunda-se o entendimento sobre ordenamento do território e governança, e, paralelamente, se estabelece diálogo com a abordagem institucionalista. A pesquisa está fundamentada em uma análise crítica, com a investigação de acontecimentos, processos e instituições do passado, para verificar sua influência na sociedade contemporânea, partindo da premissa de que tanto a realidade quanto as instituições, além 
de não serem estáticas, são contraditórias e dialéticas entre si. Algumas questões metodológicas e instrumentos teóricos respaldam a análise.

Para responder às questões postas, foram feitos levantamentos bibliográficos em fontes secundárias da Chesf, da Codevasf, da Agência Nacional de Águas (ANA) e do Ministério da Integração Nacional, pesquisas em documentos existentes e em fontes primárias, bem como foram obtidos dados em pesquisas de campo.

Adicionalmente, foram feitas entrevistas com o coordenador do estudo de transposição Sociedade Brasileira para o Progresso da Ciência (SBPC) -, em instituições de pesquisa como a Fundação Joaquim Nabuco (Fundaj), universidades e órgãos que direta ou indiretamente estão envolvidos com a questão do uso da água na área.

Este trabalho está organizado em quatro etapas. A primeira parte expõe uma visão geral do tema tratado; a segunda está centrada na reflexão sobre o ordenamento territorial e a governança, associadas à política do governo; a terceira parte explana sobre a transposição e a governança; por fim, delineiam-se os principais resultados.

\section{Reflexão teórica: uma relação intrínseca}

É possível pensar o espaço por meio de vários prismas, e como geógrafos ou profissionais do ordenamento do território, conforme sugere Ferrão (2011), não podemos perder de vista a necessidade de trabalhar com várias escalas simultaneamente. Nessa etapa, a proposta é pensar o espaço, a governança e o ordenamento territorial, conjuntamente, a partir da escala regional do nordeste semiárido brasileiro.

Para tanto, consideramos uma possibilidade de interpretação que associa a política pública da transposição do São Francisco e a governança e sua interação com a dinâmica econômica, política, social e o papel do Estado.

Ao tratar de uma realidade brasileira, optamos por entender incialmente o papel assumido pelo Estado em dois momentos históricos da política regional brasileira aqui enfocados. 0 primeiro momento seguia o modelo do keynesianismo e o segundo, o modelo neoliberalismo. 
$\mathrm{Na}$ escala de planejamento regional, esteve a Superintendência de Desenvolvimento do Nordeste $^{3}$ (Sudene), no final dos anos 1950, que, sem dúvida, trabalhava conjuntamente com a Companhia Hidrelétrica do São Francisco (Chesf), a Companhia do Vale do São Francisco (CVSF) e o Banco do Nordeste, posto que as estratégias de crescimento econômico estavam calcadas tanto na industrialização como na implantação de sistemas agrícolas modernos.

Com base nessa política de incentivos, houve, sem dúvida, avanço representado pela ruptura com a política de açudagem, embora, mais uma vez, "não se question[ass]e a existência da grande propriedade, nem tampouco a fragilidade da classe trabalhadora e as relações de produção perversas" (Gomes, 1995, p.74). Com tal postura, as ações do governo assumiram os contornos da ideologia da classe dominante da região. Veblen (1965, p.178179) vincula instituições a tipos de caráter, ou seja, a tipos humanos, já que as instituições selecionam os tipos humanos que são mais adequados. Dialogando com a teoria, Domingues (2014) entende que, no Nordeste brasileiro, o poder histórico dos coronéis, e hoje o coronel moderno, representado por grupos políticos influentes, mantém o mesmo discurso e domínio sobre a região.

Para Andrade (1983, p.23), não se devem confundir "os interesses e as aspirações do Nordeste com os interesses e as aspirações da classe dominante, que se beneficia do subdesenvolvimento". Nesse caso, as organizações que definiram o padrão institucional na região estavam influenciadas pelo jogo de poder entre as oligarquias dominantes dos nordestes (canavieiro-têxtil e algodoeiro-pecuário) e, ainda, do centro-sul, marcando presença em todas as etapas do processo.

Ainda nesse contexto, Ferrão (2011, p. 34-7) chama a atenção para o fato de que se torna evidente a existência de diferentes modelos sociais e sistemas de ordenamento do território, que são acompanhados e condicionados pela ocorrência de diferentes culturas, crenças e percepções predominantes no nível dos cidadãos que condicionam o funcionamento e os resultados dos sistemas de ordenamento do território e, em menor grau, neles refletem.

\footnotetext{
${ }^{3} \mathrm{O}$ modelo da Sudene para reduzir desigualdades entre o Nordeste e Sudeste do país foi inspirado no planejamento italiano (Mezzogiorno).
} 
Ferrão (2011, p. 34-7) admite ainda, para uma análise dessa dimensão, ser imprescindível considerar a variável tempo. Esse entendimento remete a North (1993), quando reforça a importância de considerar as normas informais de uma sociedade que, direta ou indiretamente, influenciam a criação das instituições. Em Veblen (1965), também encontramos um paralelo, quando ele mostra que se deve considerar o indivíduo, as ideias e percepções particulares, pois tais particularidades influenciam a criação de instituições, que se misturam e complementam o processo de ordenamento territorial.

Especificamente, em torno do rio São Francisco é possível observar um padrão institucional, e três usos refletem de modo claro esse padrão e controle do espaço: a geração de energia elétrica, a partir do rio São Francisco - rio localizado na região semiárida, com nascentes e afluentes em regiões de clima tropical de altitude -, com a Companhia Hidrelétrica do São Francisco (Chesf); a irrigação, com a Companhia de Desenvolvimento do Vale do São Francisco (Codevasf); e, na atualidade, a transposição de águas do rio São Francisco. Tais usos remetem ao fato de que nessa região existe escassez relativa de água e, consequentemente, uma demanda não atendida, o que certamente gera conflitos a partir dos múltiplos usos da água.

É pertinente lembrar que o arranjo institucional descrito - à exceção da última política pública - seguia o modelo keynesiano, quando o Estado do Bem-estar Social assumia o papel de planejador e empresário no comando da economia e mantinha o controle do espaço. Com a crise da economia mundial dos anos de 1970-80, o modelo mostrou sinais claros de que não atendia às novas necessidades. A década de 1990 tornou-se um marco, e, como resultado, o Estado abandonou sua trajetória histórica de responsabilizar-se por investir em setores estratégicos, presumindo poder transferir a responsabilidade dos investimentos para empresas privadas (Domingues, 2013).

Qualquer que seja o processo de planejamento, políticas públicas ou ordenamento do território, faz-se necessário oficializar sua condução via leis e decretos que viabilizem sua implementação. Então, o que são as instituições? Para Veblen (1965, p.178-179), o conceitochave da corrente institucionalista está na própria concepção de instituição como conjunto de ideias, modos de pensar compartilhados, passíveis de ser identificados e mutáveis no tempo e no espaço. A instituição definia-se como um modo de conceber a organização da 
vida em comum. Dessa forma, as instituições são vistas como ordenadoras das ações políticas, e fazem parte do processo que oficializa medidas pensadas em determinado plano de ordenamento territorial (Domingues, 2015).

Se as instituições têm papel de organizar a vida em sociedade e o ordenamento do território é entendido como política pública criada em determinado contexto social, então é possível pensá-los numa relação intrínseca. Contudo, no momento, sem desconsiderar os elementos anteriores, propõe-se uma nova forma de condução, uma nova forma de governar, que vem acompanhada de participação, a governança. Para Carmo (2014, p.42), a governança territorial é um conceito amplo e encontra-se num campo conceitual particular: o território, que é um objeto complexo, e governar, gerir as dinâmicas territoriais, torna-se difícil, tendo em vista a multiplicidade de atores. Este aspecto é claro no processo que antecede a implementação do Projeto de Transposição.

Dando sequência a esse entendimento, no início do século XXI, vários autores (Ascher, 2001; Jouve, 2005 apud Chamusca, 2013) sublinharam a ideia de que a sociedade contemporânea se transforma rapidamente, colocando novos desafios à governação dos territórios e obrigando a repensar modelos e estratégias de organização política, econômica e social. Para Chamusca (2013), ganhou destaque a valorização de processos deliberativos e regulatórios, bem como a emergência de modelos de governação em que o Estado deixa de ser o único ator envolvido na gestão dos territórios ou pelo menos de ter claro predomínio.

Existe uma multiplicidade de conceitos e definições de governança, ao mesmo tempo em que existem muitas aplicações e significados, segundo Rhodes (apud Chamusca 2013). Apesar da variedade de dimensões, optamos por pensá-la do ponto de vista do envolvimento da sociedade. Esse modelo de governança envolve múltiplas forças que, de forma simplificada, seria uma equação composta por três elementos na definição de políticas: o Estado, a sociedade civil e o setor privado. Então, questiona-se: No processo que antecedeu a decisão final do governo com relação à transposição, existiu de fato a participação da sociedade nos debates? 


\section{Rio São Francisco e os múltiplos usos: contradições e desafios}

Em que pesem algumas limitações, a água que temos poderia ser suficiente se estivesse distribuída de maneira equilibrada e houvesse boa gestão, entretanto, há zonas no Nordeste semiárido onde a água é relativamente abundante, a bacia do São Francisco é um exemplo disso, enquanto em outras áreas, a escassez dificulta a forma de vida.

A disponibilidade hídrica é condicionada pela incidência do sol, que na região do Submédio São Francisco (Figura 1) atinge cerca de 3.000 horas/ano e $400 \mathrm{~mm}^{4}$ de precipitação/ano. Essas condições explicam o elevado nível de evaporação nos reservatórios. A variação desses índices é significativa, uma vez que alteram de $419 \mathrm{~mm} / \mathrm{ano}$ no Alto São Francisco a $1.630 \mathrm{~mm} / \mathrm{ano}^{5}$ no Submédio curso, local de retirada da água para a transposição.

A capacidade total de acumulação de água superficial do Nordeste é de 85,1 bilhões de metros cúbicos. Desses, 50,3 bilhões encontram-se em reservatórios que se localizam na bacia do São Francisco (Figura 2).

O reservatório de Três Marias (fora da região Nordeste, porém na Bacia), acumula outros 19,3 bilhões de metros cúbicos (Brasil, 2003). Desses reservatórios, apenas os de Três Marias e Sobradinho, além da grande capacidade de acumulação e produção de energia, têm a função de regularização anual do rio, isto é, possuem ciclos de enchimento e esvaziamento superiores a um ano. Essa se torna uma informação importante no debate de retirada de água.

\footnotetext{
${ }^{4}$ Para Manuel Correia de Andrade e Gisélia Potengi, em trabalho para a Sudene (1980, p.9), "esse total diminui de oeste para leste, passando a 2.600 horas/ano a jusante de Cabrobó".

${ }^{5}$ Esse valor é obtido calculando-se a média da evaporação existente em Sobradinho, Itaparica e Paulo Afonso/Moxotó.
} 


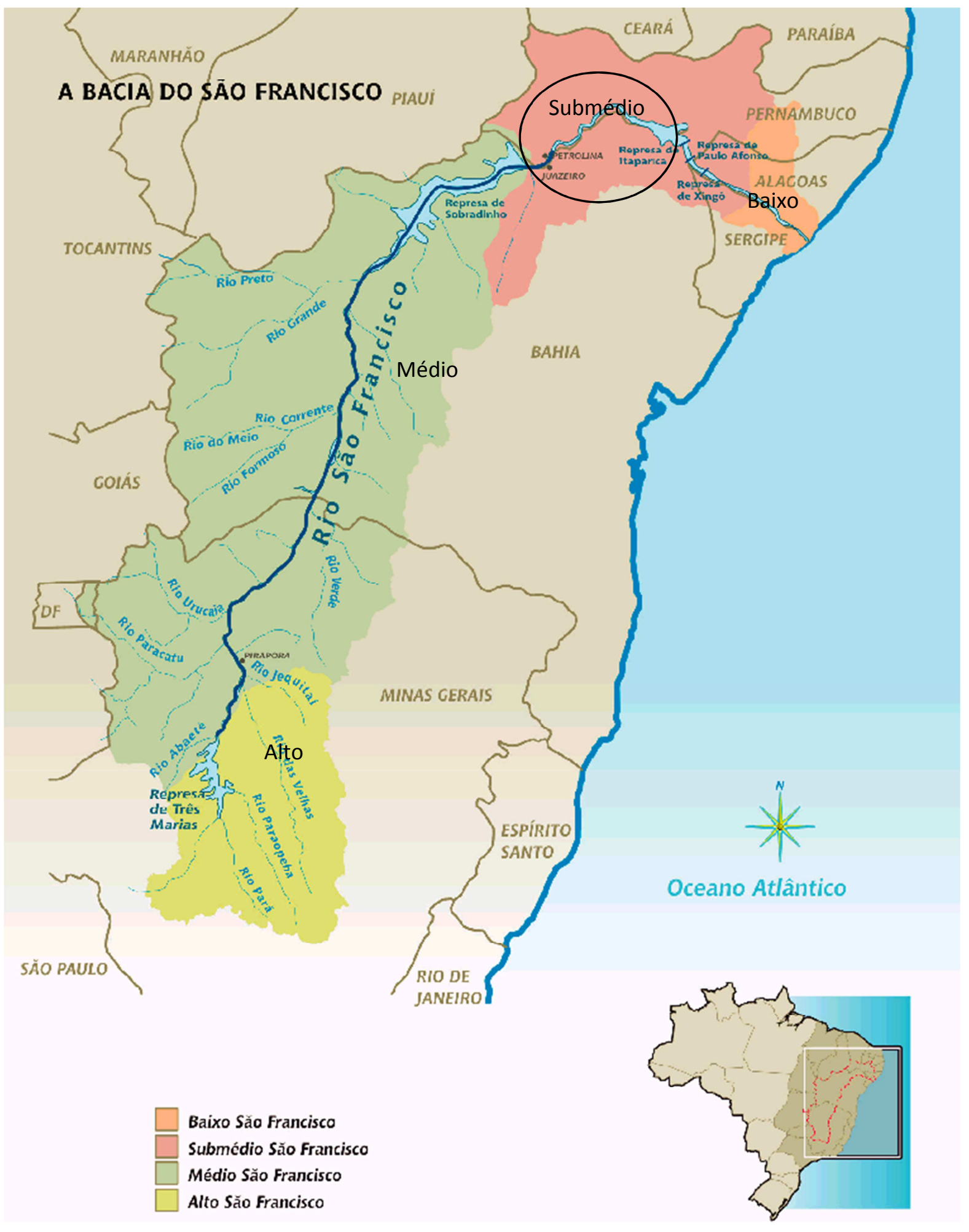

Figura 1 - Bacia do São Francisco

Fonte: Chesf, 2004. 


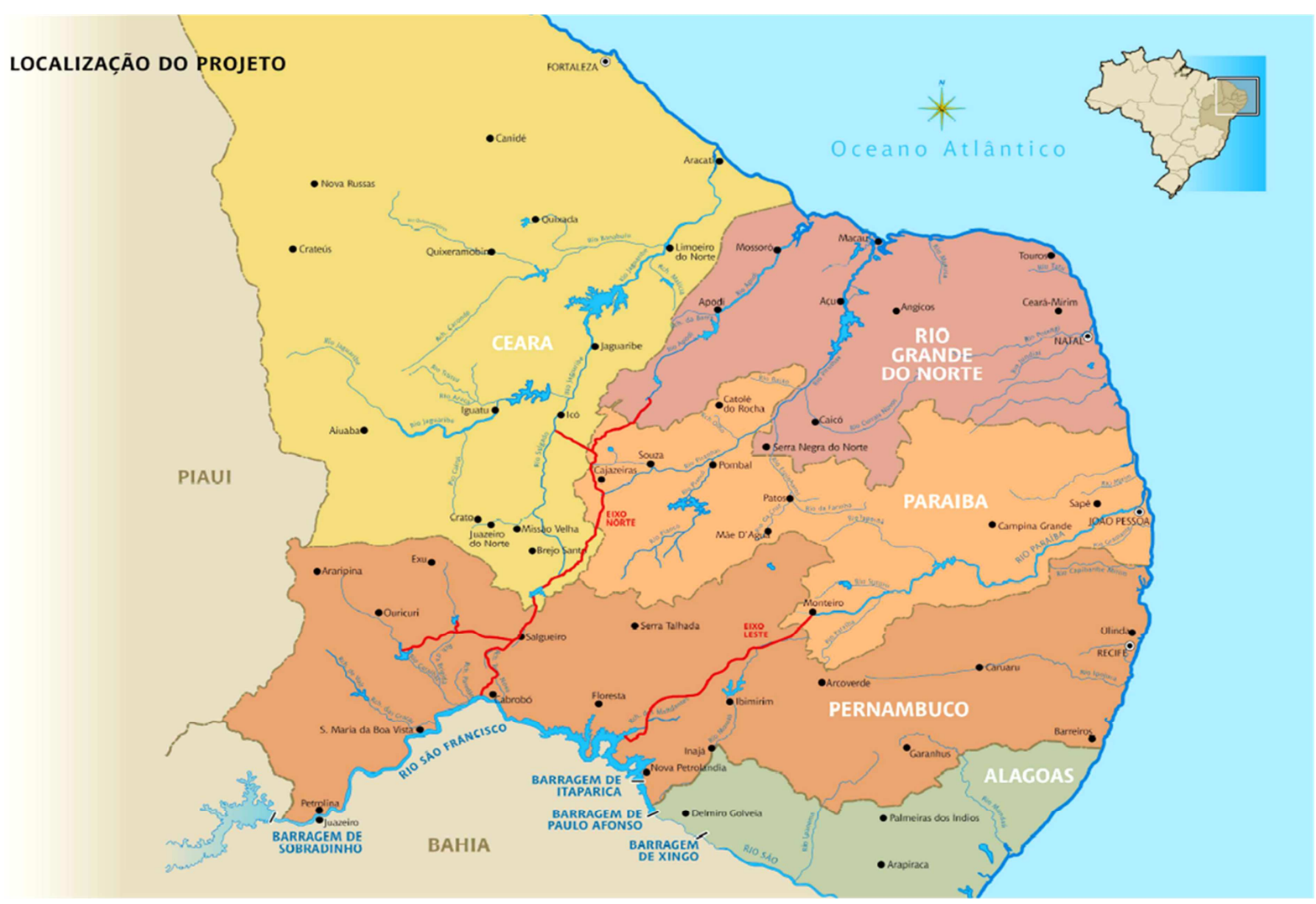

Figura 2 - Transposição do São Francisco

Fonte: Ministério da Integração Nacional, 2004.

\subsection{Transposição e o processo de governança}

\subsubsection{Projeto de engenharia}

A estiagem acompanhando a história da região semiárida nordestina. Na busca dos problemas reais e de soluções, foram instituídas organizações e políticas públicas, e a mais recente é o projeto governamental de transposição de parte das águas do rio São Francisco, que foi apresentado como alternativa para reduzir a oferta desigual de água na região sertaneja (Brasil-EIA/Rima, 2000). Sua primeira etapa prevê a construção de gigantescas tubulações e canais, num percurso de $1440 \mathrm{~km}$ de extensão, cujo objetivo, segundo o governo, é dar segurança hídrica a uma população de 12 milhões de pessoas e irrigar o sertão dos estados do Ceará, Rio Grande do Norte, Paraíba e Pernambuco - estados nordestinos.

São dois eixos previstos. O Eixo Norte $\left(402 \mathrm{~km}\right.$, transpondo $\left.45,2 \mathrm{~m}^{3} / \mathrm{s}\right)$ terá a água transportada por canais de concreto ou leitos naturais de rios até os açudes de Castanhão 
(CE) e Armando Ribeiro Gonçalves (RN) (Figura 2). No Eixo Leste (220km, transpondo $\left.18,3 \mathrm{~m}^{3} / \mathrm{s}\right), 63 \%$ de uso de água são para abastecimento humano de cidades e distritos do Agreste do estado de Pernambuco e da Paraíba, conforme a Figura 2. Esses espaços têm os piores índices de sustentabilidade hídrica do país, e suas reservas encontram-se exauridas, como apontam estudos. Para equacionar o problema, o Plano de Recursos Hídricos do Estado propõe a transposição.

Nessa concepção de derivação, o rio dividirá suas águas com riachos e ribeirões, que se tornarão perenes com a retirada média de $65 \mathrm{~m}^{3} / \mathrm{s}$ de sua vazão. Esse projeto tinha custo inicial previsto de aproximadamente $R \$ 4,5$ bilhões (cerca de 1 bilhão de euros). Hoje 0 empreendimento não se encontra concluído, seu valor duplicou e não inclui a construção de barragens e infraestrutura secundária ao longo do percurso.

\subsubsection{Estudos e pareceres}

Não se pretende aqui avaliar elementos que apontem para erros ou acertos do projeto, e sim verificar se, durante o processo que antecede as obras de engenharia, houve discussões entre os três elementos que compõem a governança, Estado, sociedade civil e o setor privado. Este será um olhar, diante de tantos outros que possam existir.

Em projetos de transposição de bacias, precisam ser considerados vários elementos em seu conjunto. Por sua complexidade, projetos dessa natureza vêm despertando passionalidade entre proponentes, que discutem a excelência técnica dos projetos e benefícios econômicos, e oponentes, que apontam os altos custos sociais e ambientais.

Nesse sentido, nossa pergunta é: Houve envolvimento dos municípios, da região, do Comitê da Bacia, de entidades acadêmicas, por meio de seus representantes?; Foram feitos estudos pela sociedade organizada e levados em consideração na decisão final?

Em todo o estudo, a discussão será centrada no processo de negociação vinculado à governança. Metodologicamente, no primeiro momento, serão considerados alguns elementos, tais como a disponibilidade e a retirada de água, a restrição de expansão da irrigação às margens da bacia de origem, apontada como principal usuário consuntivo, para em seguida abordar o impacto na geração de energia elétrica. 
No segundo momento, o trabalho concentrar-se-á nas questões relativas à bacia de destino e, por fim, tratar-se-á a degradação/revitalização. Vale lembrar que, na prática, essa divisão restrita não é possível, porque as ações e os usos, apesar de individualizados, operacionalizados por organizações específicas, misturam-se e se complementam, ou seja, caminham paralelamente, tocando-se em vários momentos.

Para isso, serão utilizados os estudos do Plano Estadual de Recursos Hídricos do Rio Grande do Norte, realizados em parceria com a Universidade Federal do Rio Grande do Norte (UFRN), os da Sociedade Brasileira para o Progresso da Ciência (SBPC) ${ }^{6}$, entrevistas com representantes de organizações envolvidas e acadêmicos. São considerados, ainda, concepções de estudiosos da hidrologia brasileira, a visão do Comitê da Bacia do Rio São Francisco (CBHSF), a posição da Agência Nacional de Águas (ANA) e da CHESF e, como não poderia deixar de ser, o projeto do governo com seus argumentos.

O Estado, por meio do Ministério da Integração Nacional, torna público o projeto e, a partir daí, os debates e discussões acontecem em todo o país.

Com relação à disponibilidade de água e à retirada prevista no projeto, especialistas apontam que, se o rio São Francisco tem vazão média de longo período de $2.850 \mathrm{~m}^{3} / \mathrm{s}$ e em Sobradinho - Submédio curso - de $1.850 \mathrm{~m}^{3} / \mathrm{s}^{7}$, é possível afirmar que a retirada média de $65 \mathrm{~m}^{3} / \mathrm{s}$ passará despercebida em termos de volume de água.

Com base nesses números, entende-se que os recursos hídricos no São Francisco são abundantes, quando confrontados com a grande maioria dos rios situados no Sertão. Contudo, quando comparados às demandas potenciais de seus múltiplos usos, especificamente na região do Submédio curso, ou ainda externos a esta, percebe-se a nítida necessidade de uma alocação planejada.

Nesse caso, por determinação do Instituto Brasileiro de Meio Ambiente (IBAMA), a vazão mínima na foz está limitada a $1.300 \mathrm{~m}^{3} / \mathrm{s}$. Tomando-se a vazão regularizada garantida pelos

\footnotetext{
${ }^{6}$ O Workshop sobre Transferência de Águas entre Grandes Bacias Hidrográficas - Rio São Francisco foi realizado no período de 02 a 04 de agosto de 2004, na UFPE, tendo sido, entretanto, o documento lançado em outubro de 2004. Nova discussão sobre o tema aconteceu na Reunião da SBPC, realizada em fevereiro de 2005.

${ }^{7}$ Para a ANA, a vazão regular mínima de $2.060 \mathrm{~m}^{3} / \mathrm{s}$ não incluía a década de 1990 . A vazão de $1.815 \mathrm{~m}^{3} / \mathrm{s}$ foi adotada a partir da reavaliação das retiradas de água, com a inclusão, na série histórica, da baixa do São Francisco, no ano de 1987.
} 
reservatórios $\left(1.850 \mathrm{~m}^{3} / \mathrm{s}\right)$ como base e deduzindo-se o limite mínimo na foz $\left(1.300 \mathrm{~m}^{3} / \mathrm{s}\right)$, resta uma vazão alocável para todos os usos consuntivos na bacia de $550 \mathrm{~m}^{3} / \mathrm{s}$, ou seja, $30 \%$ da vazão garantida produzida por ela.

Nesses termos, o Plano de Recursos Hídricos da Bacia Hidrográfica do São Francisco (PRHBSF), adota como vazão máxima alocável para usos consuntivos $360 \mathrm{~m}^{3} / \mathrm{s}$ em vez de $550 \mathrm{~m}^{3} / \mathrm{s}$ restantes. A justificativa está associada à operação dos reservatórios de Três Marias e Sobradinho, os quais estão sujeitos às contingências do setor elétrico. Com esse limite máximo alocável, as retiradas previstas pela transposição tornam-se significativas, uma vez que o projeto estabelece como retirada média a captação de $65 \mathrm{~m}^{3} / \mathrm{s}$.

Partindo desse parâmetro, os debates se alargam pelo país e, segundo Aziz Ab'Saber ${ }^{8}$ (2005), um projeto dessa ordem envolve a necessidade obrigatória do conhecimento da dinâmica climática regional do Nordeste. Nesse caso, há de se ter consciência de que o período de maior necessidade será aquele em que os rios sertanejos intermitentes perdem correnteza por de cinco a sete meses. Porém, segundo o autor, trata-se do mesmo período em que esse rio se torna menos volumoso e mais esquálido, havendo, paralelamente, maior necessidade de reservas, tanto para operar as hidrelétricas regionais quanto para atender os projetos de irrigação já instalados no Submédio (102.000ha e crescimento em torno de $4 \%$ a.a.).

O autor (2005) chama a atenção para a flexibilidade na retirada de água. A exemplo, segundo ele, grandes açudes foram construídos nos estados receptores, ao longo de muitas décadas, com suficiente volume para armazenar "as sobras de água do São Francisco" e, posteriormente, liberá-las de modo gradual. Talvez por essa razão, a ANA decidiu recomendar estudos que considerem a hipótese de bombeamento flexível: "mínimo" e "máximo". No modo mínimo, o bombeamento seria de apenas $26 \mathrm{~m}^{3} / \mathrm{s}$ para abastecimento das populações. No modo máximo, seria realizado bombeamento adicional de $101 \mathrm{~m}^{3} / \mathrm{s}$, durante 21 horas por dia, para enchimento dos reservatórios da região receptora.

\footnotetext{
${ }^{8}$ Professor da Universidade de São Paulo (USP), reconhecido por sua competência.
} 
Usando a estatística das médias de vazão do rio, Guimarães ${ }^{9}$ (2004) reitera os argumentos, indicando que a possibilidade de cheia no rio só existe em um (1) a cada 11 anos. Essa realidade dificulta a obtenção de sinergia hídrica na área, ou seja, a garantia da disponibilidade de água de forma permanente e contínua por tempo indeterminado, apontada pelo governo. Então se questiona: E a irrigação comercial exportadora ficará sujeita a interrupções em seu fornecimento? Nesses termos, seria viável economicamente?

Apesar dos argumentos contrários de representantes da academia, houve avanço, posto que nos vários projetos governamentais a nível regional não havia a discussão com qualquer segmento da sociedade.

A segunda questão a ser administrada diz respeito às outorgas de direito de uso da água já emitidas para os rios perenes da bacia. Tal situação aponta para um cenário preocupante, caso não haja aumento das vazões alocáveis, principalmente, pela reavaliação do volume disponibilizado para a geração de energia, irrigação e o limite mínimo estabelecido pelo Ibama. Nesse ponto, como resolver esta equação?

$\mathrm{O} \mathrm{CNRH}^{10}$ descredenciou a decisão do Comitê e permitiu a alteração do volume de utilização da água. Essa decisão compromete o pacto federativo, desconsiderando decisões formais dos estados envolvidos no processo, por meio do Comitê de Bacia.

O impasse é entendido como um conflito institucional de usos da água, uma vez que o poder de decisão do comitê é legítimo, apoiado no novo Modelo Institucional dos Recursos Hídricos - Lei n.ㅇ 9.433/97, art. 7ํ (V e VIII) e art. 8ㅇ․ Essa lei, ao estabelecer a Política Nacional de Recursos Hídricos, instituiu os comitês de bacia como os legítimos fóruns decisórios das ações a ser implementadas sobre um determinado corpo hídrico.

Mas a visão pode ser mais abrangente, incorporando e combinando outras variáveis. A quantidade de água, sem dúvida, é um elemento fundamental, à medida que implica menor disponibilidade para outros usos. O potencial total de geração de energia em operação na bacia do São Francisco é avaliado, segundo a Chesf, em 10,4 milhões de kW/ano (incluindo o parque termelétrico). Desse total, $95 \%$ situam-se no terço inferior da calha do rio São

\footnotetext{
${ }^{9}$ Professor da Universidade Federal do Rio Grande do Norte e ex-diretor do Instituto de Gestão de Águas do RN.

${ }^{10}$ Conselho Nacional de Recursos Hídricos.
} 
Francisco, compreendendo as usinas hidrelétricas de Sobradinho, Itaparica, Moxotó, Complexo Paulo Afonso e Xingó. ${ }^{11}$ Só essa última, situada a menos de $200 \mathrm{~km}$ da foz, responde por $30 \%$ da geração de energia (Figura 2).

É certo que as barragens ali implantadas são fatos pontuais, mas a energia produzida e transmitida para todo o Nordeste constitui um tipo de planejamento da mais alta relevância. Dessa forma, o novo projeto não poderia prejudicar o mais antigo, e sim buscar formas de conciliação. Nessa equação de disponibilidade/retirada/geração de energia, é pertinente lembrar que a demanda por energia no Nordeste é sempre crescente, e a água disponível é relativamente constante.

Segundo o governo e a própria Chesf, a redução na geração de energia poderá ser compensada com a produção de usinas termelétricas ora instaladas na região ou por usinas hidrelétricas, desde que localizadas em outras bacias, cuja transferência será feita via linhas de transmissão monitoradas pelo Sistema Interligado Nacional. Não há dúvida de que os resultados apontam para a eficiência na transferência de energia entre regiões, desde que não exista racionamento na bacia de origem. Por outro lado, à luz da engenharia, o problema será resolvido, mas se faz necessário considerar o custo final do MW originário da termelétrica, comparado ao originário do sistema hidrelétrico. Hoje, ano de 2015, o aumento na tarifa de energia elétrica no país é da ordem de $78 \%$ até julho, exatamente para fazer face ao uso da energia advinda de termelétricas.

Com base nesses dados, a equação é relativamente simples. Por um lado, há duas necessidades: a de ampliação do parque gerador para atender à demanda regional crescente e, com a transposição, energia necessária ao bombeamento da água para vencer alturas. Por outro, paralelamente e na contramão, o potencial gerador de energia do rio encontra-se praticamente esgotado, com sinais visíveis de exaustão (crise energética de 2001, 2015), e a retirada prevista de até $127 \mathrm{~m}^{3} / \mathrm{s}$ para translado de águas do São Francisco. Nesses termos, faz-se necessário decidir o que é prioritário.

\footnotetext{
${ }^{11}$ De Sobradinho a Paulo Afonso, estamos no Submédio, enquanto Xingó encontra-se no Baixo curso. Hoje o governo considera os novos limites no projeto (GEF) de transposição, segundo os quais o Submédio se estende até Xingó. Segundo a Chesf, esses novos limites ainda não são oficiais.
} 
Entende-se, pois, que tal projeto, se concretizado nos moldes propostos, antecipará um problema já previsto, de necessidade imediata na definição de uma nova matriz energética para a região, por meio do aporte de novas fontes de energia. Contudo, os últimos governos "não apresentaram nenhum plano decenal para o setor elétrico, nem projeções da matriz energética", como atesta Bajay ${ }^{12}$ (2004).

O que se observa até este ponto é que o debate através das organizações governamentais, segundo suas especialidades, foi positivo, entretanto, está presente não apenas uma inconsistência dos dados oficiais, mas também uma divergência de informações numéricas, e, nesse embate, algumas concordam com o projeto do governo, enquanto outras argumentam a necessidade de maior amadurecimento. Percebe-se, ainda, a ausência no debate do setor privado e da sociedade.

Outra reflexão proposta no trabalho diz respeito à realidade nas áreas de destino. $\mathrm{A}$ transposição, segundo o governo, trará segurança hídrica aos rios Salgado, Jaguaribe (CE) por meio da interligação da infraestrutura existente - e Piranhas-Açu (PB e RN), no Eixo Norte, e Moxotó e Brígida, no Eixo Leste.

Então, surge um questionamento do ponto de vista socioeconômico: Quem leva vantagem no translado?; As empresas agrícolas voltadas para exportação de fruticultura?; Seria a segurança hídrica empresarial a prioridade?; Como entender o objetivo central do projeto do governo de garantir abastecimento humano?

Os fatos levam a crer na reprodução da grande propriedade na área. Os antigos latifundiários foram substituídos por grandes empresários capitalistas, nacionais e multinacionais, com interesses agropecuários beneficiados pelo Estado. No entanto, é importante ressaltar que a economia baseada na pequena propriedade (de 3ha a 6 ha) tem respostas lentas, se comparada ao agronegócio, mas é fundamental para a manutenção do homem no campo.

De acordo com Guimarães (2006), as duas maiores represas do Nordeste ficam exatamente no Ceará e no Rio Grande do Norte. A represa Castanhão (CE) ${ }^{13}$ o maior açude público do

\footnotetext{
12 Professor do Departamento de Energia da Universidade de Campinas (Unicamp).

${ }^{13}$ Construída pelo DNOCS durante o governo Fernando Henrique Cardoso, a represa responderá sozinha por um aumento de quase $40 \%$ de todo o volume $\left(\mathrm{m}^{3}\right.$ ) acumulado desde o início do século (GARRIDO, 1999).
} 
Brasil, tem capacidade de armazenamento ${ }^{14}$ de 4,2 bilhões de metros cúbicos e potencial para abastecer a região metropolitana de Fortaleza e o Baixo Jaguaribe, com vazão regularizada de $57 \mathrm{~m}^{3} / \mathrm{s}^{15}$

Torna-se pertinente apontar que a oferta de água no estado do Ceará é de aproximadamente $215 \mathrm{~m}^{3} / \mathrm{s}$. O estado inteiro consome $20 \mathrm{~m}^{3} / \mathrm{s}$, além de possuir um importante projeto de interligação de suas bacias para atender às necessidades internas. Esse estado possui, segundo informações, aproximadamente metade da água represada da região Nordeste, que dispõe de 37 bilhões de metros cúbicos em seus açudes. É interessante ressaltar que, mesmo no debate sobre quem se beneficiará do projeto, não se percebe a participação de representantes do capital privado.

No Rio Grande do Norte, apenas a barragem Armando Ribeiro Gonçalves, a segunda maior barragem do Nordeste, armazena 2,4 bilhões de metros cúbicos de água, com vazão regularizada de $17 \mathrm{~m}^{3} / \mathrm{s}$. A matemática indica a capacidade de atender várias vezes ao consumo de $6 \mathrm{~m}^{3} / \mathrm{s}$, necessário para o abastecimento de toda a população potiguar durante vinte anos. ${ }^{16}$ Contraditoriamente, as regiões do Seridó (RN) e Inhamuns (CE) são carentes e não serão beneficiadas pelo projeto. Segundo dados do Primeiro Plano Estadual de Recursos Hídricos do Rio Grande do Norte (Rio Grande do Norte, 2000), 90\% do déficit hídrico total do estado estão concentrados na sub-bacia do rio Seridó, excluída da rota da transposição. O que dizer da falta de mobilidade da sociedade dessa área em exigir providências nesse sentido? Percebe-se, pois, que o debate fica restrito às organizações e academias.

Com base em análises dos planos estaduais de recursos hídricos desses estados, até 2025, a demanda e a disponibilidade de água se encontram em níveis satisfatórios, o que de certa forma não invalida ações de longo prazo, desde que exista a plena sinergia hídrica local, com a interligação dos reservatórios ora existentes e a otimização de sua operação, se necessário for, combinada com a efetiva disponibilidade na bacia de origem.

\footnotetext{
${ }^{14} \mathrm{Na}$ literatura existente, a capacidade de armazenamento dessa barragem varia, sendo ora de 4,2 bilhões de $\mathrm{m}^{3}$, ora de 6,7 bilhões de $\mathrm{m}^{3}$.

${ }^{15}$ Secretaria de Recursos Hídricos do Ceará. O Ceará acumula sozinho 18 bilhões de $\mathrm{m}^{3}$. O volume de água do Castanhão é superior ao do reservatório de Xingó (1,1 vezes). O Rio Grande do Norte detém 3 bilhões de $\mathrm{m}^{3}$.

16 Plano Estadual de Recursos Hídricos do Rio Grande do Norte (2000).
} 
Quanto ao Estado da Paraíba, apesar de ter capacidade de armazenamento, hoje, de 930 milhões de metros cúbicos armazenados, não possui infraestrutura eficiente (adutoras) para levar água para os locais mais secos. A oferta nesse estado está aquém dos outros dois em questão, com apenas $32 \mathrm{~m}^{3} / \mathrm{s}$, e demanda de $21 \mathrm{~m}^{3} / \mathrm{s}$.

O governo, por sua vez, monta uma estratégia para defender seu ponto de vista, afirmando que "é uma questão de segurança hídrica e que a estrutura para receber e armazenar essa água já existe e o restante viria através de outros programas integrados ao projeto, como o 'PRÓÁGUA semiárido', 17 que prevê a construção de adutoras". No entendimento de Rebouças $(2004)^{18}$, trata-se de uma política imediatista, para gerar votos. Em nosso entendimento, de forma geral, é perceptível a falta de infraestrutura para otimizar o que já existe, a necessidade de melhor gerenciamento e de uma ampla e eficiente política de educação.

Por outro lado, Rebouças (2003) chama atenção para dois novos elementos independentes da redução na geração de energia. O primeiro envolve problemas de ordem física, com aumento do volume de água desperdiçada na região. Naquele momento, "eram 2 mil metros cúbicos de água passando naquele ponto do rio São Francisco - em Cabrobó, Pernambuco -, local de onde a água será desviada, e num caminho maior que o atual, o que vai gerar maior evaporação e salinização". Acrescenta-se que, na realidade, as evidências são claras, com açudes subutilizados, problemas de salinização devido à evaporação intensa, e, como resultado, a água estocada degrada-se e torna-se imprópria para o consumo humano e uso na agricultura. Entendemos que o fator evaporação é um ponto obscuro do projeto.

Cabe lembrar, ainda, que não basta a construção de reservatórios e açudes, as ações instrumentais das organizações precisam ir além, viabilizando infraestrutura para o uso no longo prazo. Nesse quesito, o governo federal construirá os dois eixos principais, enquanto a

\footnotetext{
17 'PRÓÁGUA semiárido' - decreto n.o 3.057, de 13 de maio de 1999 - , programa de alimento e garantia de água à população atingida pela estiagem. Criado em 1998 (Sudene), teve em novembro de 2003 seu prazo prorrogado até 31 dezembro de 2005. Tornou-se um dos pontos principais do Programa Brasil em Ação, abrangendo a construção de obras hídricas consideradas fundamentais. Enfim, é um programa de gestão de recursos hídricos do governo federal, financiado em parte com recursos do Banco Mundial e em parte com recursos do Japan Bank for International Cooperation (JBIC).

${ }^{18}$ Nova discussão sobre o tema aconteceu na Reunião do Instituto de Tecnologia de Pernambuco, ITEP em junho de 2004.
} 
construção dos canais secundários será de responsabilidade dos governos estaduais. Isso é preocupante, uma vez que os recursos financeiros dos outros escalões, além de reduzidos, muitas vezes são mal administrados, apontando na direção de obras inacabadas.

O segundo elemento, de acordo com Rebouças (2003), diz respeito à expectativa que será gerada entre a população, que se sentirá frustrada, pois o canal levará água ao longo de eixos, e a seis quilômetros dali a situação de miséria vai permanecer igual, porque o fato de a água estar correndo pelo rio não deverá torná-la fator de bem-estar para a população.

Nesse ponto, sua afirmação concorda com a de Aguiar (2003), quando sinaliza que o projeto "não vai matar a sede de moradores do Sertão". Mas Rebouças avança e traz algo novo, ao apontar que, além da necessidade de gerenciamento eficiente na condução do uso da água do Semiárido, está presente a carência na educação - o analfabetismo -, como grande impedimento ao engajamento do processo de uso e conservação da água.

É possível ampliar a análise e incorporar a visão de Amin (2000, p.65), no que se refere à perspectiva de desenvolvimento regional para os neo-institucionalistas. Segundo essa teoria, a principal fonte de prosperidade econômica está na mobilização do potencial endógeno das regiões, em outras palavras, quando reconhece que as políticas deveriam ser formuladas de baixo e de acordo com as especificidades da área, acrescidas de uma visão de longo prazo, baseada na pluralidade de atores. É necessário, mais que tudo, um trabalho combinado de políticas locais claras e objetivas, articuladas com outras instâncias.

Nas discussões sobre a transposição na Universidade Federal de Pernambuco, em reunião da SBPC, em agosto de 2004 e fevereiro de 2005, concluiu-se que se deveria preceder à transposição o gerenciamento eficiente e à construção de adutoras para utilizar o que já existe, o que implicaria custo final menor. Aponta-se, ainda, que no Eixo Leste o alcance social é visível, enquanto o Eixo Norte beneficia projetos industriais. ${ }^{19}$ Reiterando o pensamento, Carlos Galvão ${ }^{20}$ aponta um "equívoco ao associar a transposição a pequenas propriedades e comunidades dispersas no meio rural". Então, a quem a transposição beneficiará?

\footnotetext{
${ }^{19} \mathrm{O}$ açude Castanhão foi construído para viabilizar o funcionamento do Complexo Industrial do Porto do PECEM, mas para isso depende basicamente das águas do São Francisco. Em outros termos, a transposição vem justificar o açude.

${ }^{20}$ Professor da Engenharia Civil da Universidade Federal de Campina Grande.
} 
Por fim, é analisado o enfoque ambiental. Mais da metade de vegetação nativa, nos últimos cem anos, foi devastada para produção agrícola, pecuária e produção de carvão vegetal para abastecer os fornos das siderurgias. Estima-se que foram destruídos $75 \%$ da vegetação regional e $95 \%$ das matas ciliares dos rios em seu alto curso, e com a expansão da soja o desmatamento tende a crescer.

Os impactos desse processo refletem-se nas águas pluviais, com altos picos de cheias nos rios, e, por outro lado, com períodos cada vez mais longos de vazões mínimas. Já é fato a degradação na hidrovia, de Pirapora (MG) a Juazeiro (BA), com o assoreamento impedindo a navegação.

A construção de Xingó para geração de energia provocou redução da vazão do rio, de tal modo que o mar, sem resistência da antiga força das águas, vem aos poucos penetrando rio acima, provocando crescente salinização da água. Esse é um problema sério e de difícil solução, posto que a entrada da água do mar para o interior do rio se torna maior do que as incursões naturais das águas do rio em direção ao oceano. Com a transposição, é possível que o rio São Francisco venha a ter sérios problemas comuns a bacias que vivenciam o desvio de suas águas para irrigação, e a questão ambiental de certa forma está ligada à questão econômica de médio prazo. Tal projeto será sustentável daqui a 50 anos? Esse é um debate a fazer.

Ainda, o contexto da questão ambiental, embora sem ligação direta com a transposição, diz respeito à inexistência de saneamento básico nas cidades ribeirinhas, com o lançamento no rio de dejetos humanos. Aqui cabe ressaltar que apenas $26 \%$ dos municípios possuem abastecimento de água e somente $15 \%$ dispõem de serviço de esgotamento sanitário.

Paralelamente, o governo federal tem um plano para revitalização hidro-ambiental do rio São Francisco, com a implantação de medidas mitigadoras. O estudo foi elaborado pelo Ministério da Integração Nacional (Brasil, 2009). Esse projeto prevê a ordenação da água (usos múltiplos) e a recomposição da mata em torno do leito principal e nos afluentes. Ações e obras centradas em coleta, interceptação e tratamento de esgotos sanitários estão em andamento, entretanto, até onde os dados apontam, as ações nesta direção são tímidas. 
Apesar da abertura do governo para discussões, não houve sensibilidade por parte da equipe do Ministério da Integração Nacional/governo, uma vez que se manteve o projeto original. Quanto às obras, estas se encontram em andamento, embora de forma lenta, inclusive, com períodos de paralizações ocasionadas por retirada das empreiteiras/empresas dos canteiros de obras por questões referentes à falta de pagamentos por parte do governo. Alguns canais concluídos já se encontram em deterioração, o que pode indicar a falta de qualidade construtiva.

\section{Conclusão}

Ao longo do último século, os investimentos e políticas de ordenamento territorial na região semiárida nordestina voltaram-se para ações que envolvem o uso dos recursos hídricos.

Especificamente, o governo federal instituiu o ordenamento do território numa fatia do semiárido com projeto de transposição de águas do rio São Francisco para outras bacias de regime temporário da região. Um projeto dessa dimensão, com todas suas implicações sociais, econômicas, culturais e ambientais, alcançou o âmbito do debate, das discussões públicas, favorecendo a participação da sociedade organizada.

Então, diante da perspectiva de análise proposta - a governança e o projeto de transposição -, as investigações nos levam a discorrer sobre três pontos fundamentais: o comportamento assumido pelo Estado, sociedade e setor privado. Em todo o processo, não houve envolvimento da sociedade, e sim de entidades oficiais, mediante estudos elaborados por técnicos especializados, pela academia, em debates e reuniões públicas. Houve avanço em direção à governança - posto que foi possibilitada a discussão, dentro do contexto democrático -, mas o diálogo com o Estado não ocorreu. A realidade aponta que não foram consideradas as opiniões, recomendações e preocupações de natureza racional-científica, advindas de representantes de organizações, pelo governo na decisão final.

Com relação à participação do setor privado, não se percebeu uma postura ativa, uma participação como sujeito da história, pelo menos de forma clara. Por outro lado, este setor aparece claramente na competição e negociação com o Estado para assumir as obras, por 
meio de empreiteiras/empresas para sua execução. Paralelamente, sentiu-se falta, na negociação com o Estado de uma paceria para financiar o projeto em si. Contudo, entendese que essa obra não traria retorno financeiro para o capital privado, cabendo ao Estado assumir o empreendimento em sua totalidade, contrariando o modelo neoliberal.

Postura dessa ordem leva a crer que, apesar de o governo brasileiro possibilitar a participação de diferentes atores sociais, políticos e econômicos, ou seja, propor uma gestão participativa, na prática, o resultado final não foi diferente do modelo de governo clássico, quando a decisão vinha de cima, sem consulta à sociedade.

E mais, nas recomendações emitidas pela sociedade, ficou claro que, para a execução do Projeto de Transposição de Águas do São Francisco, são de suma importância a realização de uma revisão das outorgas concedidas pela ANA e a definição de uma nova matriz energética, além de um estudo mais aprofundado das condições ambientais da bacia e de uma efetiva ação de revitalização do rio.

\section{Referências}

AB'SABER, A. A. A quem serve a transposição? In Folha de São Paulo, São Paulo, 20 fev. 2005. Brasil, Caderno B, A.18.

AGUIAR, J. P. M. Transposição - contra ou a favor? Recife: CHESF. 2003.

AMIN, A. Una perspectiva institucionalista sobre el desarrollo económico regional. Cadernos do IPPUR, Rio de Janeiro, Agoto/Dezembro 2000, vol. 14, $n^{\circ} 2$, p. 47-68.

ANDRADE, M. C. A seca: realidade e mito. Recife: Asa Pernambuco. 1983.

ANDRADE, M. C. e POTENGI, G. Dinâmica das microrregiões de intensa atividade migratória. 3 v. (População e emprego). Recife. Sudene, 1980.

BAJAY, S. V. Formulação de política pública, planejamento e regulação de mercados de energia: as visões das administrações FHC e Lula e os desafios pendentes. Campinas: Unicamp. 2004. Disponível em: http://www.consciencia.br [Consultado em 12 de junho de 2005].

BARCELOS, R. M. A Nova Economia Institucional: Teoria e Aplicações. Brasília, UnB/IH/ECO. 2003.

BRASIL. Ministério da Integração Nacional. Relatório de impactos ambientais. Brasília: Rima. 2004.

BRASIL. Ministério da Integração Nacional. Projeto de transposição de águas do rio São Francisco para o Nordeste setentrional: análise econômica e justificativa do empreendimento. Relatório. Brasília. 2004.

BRASIL. Ministério do Interior. Uma política de desenvolvimento econômico para o Nordeste. $2^{\text {a }}$ ed. Recife: Sudene. 1967.

BRASIL. Ministério do Interior. Uma política de desenvolvimento para o Nordeste. Recife: Sudene. 1985. 
BRASIL. Agência Nacional de Águas - ANA. Diagnóstico analítico da Bacia do São Francisco e zona costeira. Versão preliminar do resumo executivo. Brasília: ANA; GEF; PNUMA; OEA. 2003.

BRASIL. Ministério da Integração Nacional. Novos limites. 2004.

BRASIL. Ministério da Integração Nacional. Relatório de impactos ambientais. Brasília: Rima. 2000.

BRASIL. Ministério da Integração Nacional. Projeto de transposição de águas do rio São Francisco para o Nordeste setentrional: análise econômica e justificativa do empreendimento. Brasília. Relatório. 2000.

BRASIL. Ministério da Integração Nacional. Ações de revitalização na bacia hidrográfica do rio São Francisco. Brasília-DF, julho/2009.

BRASIL. Ministério do Meio Ambiente e Secretaria de Recursos Hídricos e Ambiente Urbano. Ações de revitalização na bacia hidrográfica do rio São Francisco. Brasília, julho de 2009. Disponível em http://www.mma.gov.br/estruturas/srhu.../152_publicacao24082009102422.pdf [Consulta em junho de 2015].

CARMO, F. Planos Regionais de Ordenamento do Território e governança territorial: do discurso às evidências da prática. GOT - Revista de Geografia e Ordenamento do Território, 2014, n 5, p.41-65. Disponível em: http://cegot.org [Consultado em novembro de 2014].

CARVALHO, O.; EGLER, C. A. G. Alternativas de desenvolvimento para o Nordeste semi-árido. Relatório preliminar. Fortaleza: Banco do Nordeste. 2002. Estudo realizado para o Banco do Nordeste. Esta versão publicada em 2003.

CHAMUSCA, P. Novos desafios e objetivos de governação territorial: discutindo a reorganização do Estado e a conceptualização da governança como modelo de gestão dos territórios. GOT - Revista de Geografia e Ordenamento do Território, 2013, $\mathrm{n}^{\circ}$ 4. Disponível em: http://www.cegot.org [Consulta em novembro de 2014].

COMPANHIA HIDRELÉTRICA DO SÃO FRANCISCO - CHESF. Transposição de águas do rio São Francisco para bacias do semi-árido nordestino. Recife. 2000.

COMPANHIA HIDRELÉTRICA DO SÃO FRANCISCO - CHESF. A CHESF e a transposição. Recife. 2004.

CBHSF. Plano de recursos hidricos da bacia hidrográfica do rio São Francisco. Módulo 1 Resumo executivo.Proposta para apreciação do Plenário do CBHSF. Salvador, 28 de junho 2004.

DIÁRIO DE PERNAMBUCO. Projeto de transposição sofre críticas por levar água a regiões úmidas do Nordeste. Recife, 17 out. 2004. Economia, Caderno B, p.12.

DOMINGUES, R. A. Aspectos institucionais da gestão dos recursos hídricos: o caso do Submédio São Francisco. Tese (Doutorado em Geografia), Universidade Federal do Rio de Janeiro, Rio de Janeiro. 2006.

DOMINGUES, R. Alcântara. Construção política da disponibilidade hídrica: o caso do sertão semiárido. GEOUSP - espaço e tempo, São Paulo, 2013, no33, pp. 153-167. Disponível em:

http://www.revistas.usp.br/geousp/article/downloadSuppFile/

DOMINGUES, R. Alcântara. Instituições e o controle do espaço: um olhar da geografia. In: XIII Coloquio Internacional de Geocrítica El control del espacio y los espacios de control. (Trabalho apresentado). Barcelona, 5-10/mayo/2014. Disponível em: http://www.ub.edu/geocrit/coloquio2014/Rita\%20Alcantara\%20Domingues.pdf

DOMINGUES, R. Alcântara. Abordagem institucional e governança territorial: um diálogo possível na geografia. In II Congresso Internacional SETED-ANTE Santiago de Compostela, Espanha. 2015.

FERRÃO, J. O ordenamento do território como política pública. Fundação Caloustre Gulbenkian - Serviço de educação de bolsas. Lisboa. 2011.

GARRIDO, R. J. Comentários sobre os aspectos institucionais do setor de recursos hídricos. Disponível em: http://www.cbvelhas.hpg.ig.com.br [Consultado em 10 de fevereiro de 2003].

GOMES, A. M. Imaginário social da seca, suas implicações para mudança social. Recife: FUNDAJ. 226p. (Estudos e pesquisa, 99). 1995. 
GUIMARÃES, João Abner. A transposição do rio São Francisco e o Rio Grande do Norte. 2006. Disponível em: http://www.fundaj.gov.br [Consultado em 03 de março de 2006].

LACAZE, J. P. O ordenamento do território. Lisboa: Instituto Piaget. 1995.

LANNA, A . E.; DORFMAN, R. Sistemas de gerenciamento de recursos hídricos: críticas e algumas propostas. Revista de Administração Pública, Rio de Janeiro, abril/junho 1993, vol. 27, n² 2, p. 63-73.

MINTER. Uma política de desenvolvimento econômico para o Nordeste. 2. ed. Recife: Sudene. 1967.

MINTER. Uma política de desenvolvimento para o Nordeste. Recife: Sudene. 1985.

NORTH, D. C. Desempeño económico enel transcurso de losaños. Conferencia en Estocolmo, Suecia, el 09 diciembre, al recibir el Premio Nobel de Ciencias Económicas. 1993. Disponível em http://www.eumed.net [Consultado em 03 de maio de 2004].

NORTH, D. C. The role of institutions in economic development discussion. Paper series, no.2, October, Geneva, Switzerland, United Nations Economic Commission for Europe. 2003.

REBOUÇAS, A. C. Transposição do rio: uma farsa hídrica. São Paulo. 2003. Disponível em http://wwwsocioambiental.com.br [Consultado em 02 de março de 2014].

REBOUÇAS, A. C. Palestra realizada no Instituto de Tecnologia de Pernambuco. 2004.

RIO GRANDE DO NORTE. Primeiro Plano Estadual de Recursos Hídricos do Rio Grande do Norte. RN. 2000.

SOCIEDADE BRASILEIRA PARA O PROGRESSO DA CIÊNCIA - SBPC. Transferência de águas entre grandes bacias hidrográficas. Relatório final. Recife: SBPC/UFPE. 2004.

SUASSUNA, J. A transposição de águas do São Francisco poderá ocasionar um "processo vaga-lume" no sistema elétrico nordestino. Recife: Fundaj. 2001.

SUASSUNA, J. Recalque e transposição de águas: equívocos nos conceitos. Recife: Fundaj. 2001a. Disponível em http://www.fundaj.gov.br [Consultado em 16 de maio de 2015].

SUASSUNA, J. Transposição do Rio São Francisco: um erro que poderá ser fatal. Recife: Fundaj. $2001 b$. Disponível em http://www.fundaj.gov.br [Consultado em 05 de abril de 2015].

SUASSUNA, J. João Suassuna fala sobre a transposição do São Francisco. 2005. Disponível em http://www.Francisco.floripa midiaindependente.org [Consultado em 22 de março de 2015].

SUASSUNA, J. Os apagões da era Lula. Recife: Fundaj. 2005a. Disponível em http://www.Francisco.floripa midiaindependente.org [Consultado em 23 de fevereiro de 2015].

VEBLEN, T. A teoria da classe ociosa: um estudo econômico das instituições. São Paulo: Pioneira. 1965. 